\title{
Utilização do resíduo de vidro de uma empresa metalúrgica para aplicação em placas de solo-cimento
}

\author{
Marlon Aparecido Alves Martins ${ }^{1}$ \\ Neilton Paixão de Jesus Junior ${ }^{1 *}$ (1) \\ Simone Pereira Taguchi ${ }^{1}$ \\ Renata Nunes Oliveira ${ }^{1}$ \\ Rui de Góes Casqueira ${ }^{1}$ \\ Luiz Antônio Borges Júnior ${ }^{1}$
}

\section{Resumo}

A indústria siderúrgica é responsável pela geração de um grande volume de resíduo sólido. Um dos principais produtos da etapa de trituração é a geração do resíduo Fluffy. O resíduo de vidro oriundo do Fluffy metalúrgico foi utilizado para produzir placas de solo-cimento. O solo e o resíduo moído de vidro foram previamente caracterizados e misturados com cimento CPV-ARI, nas proporções de 40:20:40; 50:20:30; 60:20:20; 50:10:40; 60:10:30 e 70:10:20, respectivamente, sendo prensados no formato de $120 \times 30 \times 5 \mathrm{~mm}$ de curados em água durante sete dias. As amostras foram analisadas quanto as fases cristalinas (DRX), análise morfológica (MO), massa específica (picnometria) e absorção de água, em triplicata, considerando 28 dias. O resíduo e o solo apresentaram massas específicas de 2,389 e $2,021 \mathrm{~g} / \mathrm{cm}^{3}$, respectivamente, enquanto os corpos de prova apresentaram valores médios entre 1,344 a 1,773 g/cm ${ }^{3}$. Os valores individuais de absorção de água variaram de $16,14 \%$ a $21,81 \%$, com valores médios entre $16,34 \%$ a $19,54 \%$, e a resistência à flexão média variou entre 2,22 a 4,66 MPa. Desse modo, a utilização do resíduo de vidro na produção de placas de solo-cimento tem potencial como produto sustentável.

Palavras-chave: Solo-cimento; Resíduo de vidro; Absorção de água.

\section{Glass residue from a metallurgical industry to re-utilization in soil-cement plaque}

\begin{abstract}
The steel industry is responsible for generating a large volume of solid waste. One of the main products of the milling is the generation of the waste called Fluffy. Glass residue from metallurgical Fluffy was studied for soil-cement plaque production. The soil and the grounded glass residue were previously characterized and mixed with cement CPV-ARI, according to the following proportions, respectively: 40:20:40; 50:20:30; 60:20:20; 50:10:40; 60:10:30 and 70:10:20. They were compressed $(120 \times 30 \times 5 \mathrm{~mm})$ and cured (by addition of water) for seven days. The samples (after 28 days) were analyzed to evaluate the crystalline phases (by XRD), morphological analysis (by optical microscope), specific mass (pycnometer) and water absorption in triplicates. The residue and the soil presented specific mass of 2.389 and $2.021 \mathrm{~g} / \mathrm{cm}^{3}$, respectively, while the samples presented mean values of specific mass between 1.344 and $1.773 \mathrm{~g} / \mathrm{cm}^{3}$. The samples water absorption was from 16.14 to $21.81 \%$, mean values of $16.34-19.54 \%$. The mean flexural strength varied between 2.22 MPa and 4.66 MPa. Thereby, the use of the glass residue in the production of soil-cement plaques has potential as sustainably product.
\end{abstract}

Keywords: Soil-cement; Glass residue; Water absorption.

\section{Introdução}

A indústria metalúrgica gera uma grande quantidade de resíduos sólidos, efluentes líquidos e gasosos. Em indústrias do tipo semi-integrada, ainda há a geração de resíduos como escória, pó de aciaria e carepa de laminação. A geração desses resíduos acontece em todas as etapas, mesmo durante o processo de trituração, que consiste na fragmentação de

${ }^{I}$ Departamento de Engenharia Química, Universidade Federal Rural do Rio de Janeiro, UFRRJ, Seropédica, RJ, Brasil.

*Autor correspondente: neiltonpjj@gmail.com

2176-1523 (C) 2022. Martins at al. Publicado pela ABM. Este é um artigo publicado em acesso aberto (Open Access) sob a licença Creative Commons Attribution, que permite uso, distribuição e reprodução em qualquer meio, sem restrições desde que o trabalho original seja Commons Attribution,
corretamente citado. 
qualquer produto que contenha metal, mesmo que este esteja combinado com outros materiais [1].

A sucata é processada com o objetivo de aumentar a sua densidade de metais ferrosos, remover impurezas e materiais metálicos não ferrosos. Os resíduos da trituração em Shredder consistem em dois agregados: uma mistura de vidros, cerâmicas, plásticos e metais não imantáveis e outro basicamente por terra [2-4].

No Brasil, com exceção da fração ferrosa, os demais resíduos não são aproveitados. Como resultado, as empresas siderúrgicas armazenam grandes volumes da sucata (Fluffy), que são enviados para aterros sanitários.

A Baia 1 da empresa metalúrgica em questão, conforme Figura 1, contém aproximadamente 180.000 toneladas de Fluffy, e deste pode-se extrair 827 t de vidro [3].

O setor da construção civil é um dos segmentos que mais consome insumos não renováveis em grande quantidade, além da grande produção de rejeitos industriais. Por conseguinte, a busca pela união de rejeitos industriais com materiais de construção tem sido amplamente explorada. Isto é, a inserção de resíduo de vidro na composição de placas de solo cimento apresenta uma forma sustentável de disposição de rejeitos e, possivelmente, melhorar as propriedades do produto [5].

Galvão et al. [6] pontua que a reciclagem de vidro propicia um imenso leque de possibilidades. Além de sua reutilização no genuíno processo produtivo que permite uma vantajosa diminuição da energia necessária para sua fundição, os resíduos de vidro podem ser reciclados como agregado para cimento Portland e concreto asfáltico, gerando a economia de agregados naturais comumente utilizados para este fim.

A reciclagem do vidro oriundo do Fluffy não é trivial para a indústria de vidros, pois o custo para tornar o resíduo adequado ao processo tradicional é extremamente oneroso. Isto porque o Fluffy é uma mistura de diversos materiais e terra, o que levaria obrigatoriamente a um processo de descontaminação preliminar. Além disso, o resíduo de vidro do Fluffy possui tamanhos variados de cacos, com diferentes colorações, necessitando uma triagem minuciosa para utilização na indústria do vidro. No entanto, o aproveitamento deste resíduo é viável para a utilização como constituinte em produtos cimentícios, por exemplo, a placa de solo-cimento, pois as variações da coloração, tamanho das partículas e impurezas não tem influência significativa nas propriedades da placa $[1,3]$.

A placa de solo-cimento pode ser uma alternativa às placas de granito, tradicionalmente utilizadas como revestimentos, soleiras de portas e janelas. Isso posto, este trabalho visa avaliar a possibilidade da utilização do resíduo de vidro como um dos componentes da placa de solo-cimento, na substituição do agregado miúdo (areia) normalmente utilizado no processo.

\section{Materiais e métodos}

Os materiais utilizados foram: i) o solo fornecido pela Empresa Minerais Rio Doce - SP; ii) o Cimento Portland $\mathrm{V}$ de Alta Resistência Inicial VOTORAN (CP-V ARI) fornecido pela empresa ECO REAL; e iii) o resíduo de vidro oriundo de uma baia de $267 \times 100$ m, onde são depositados
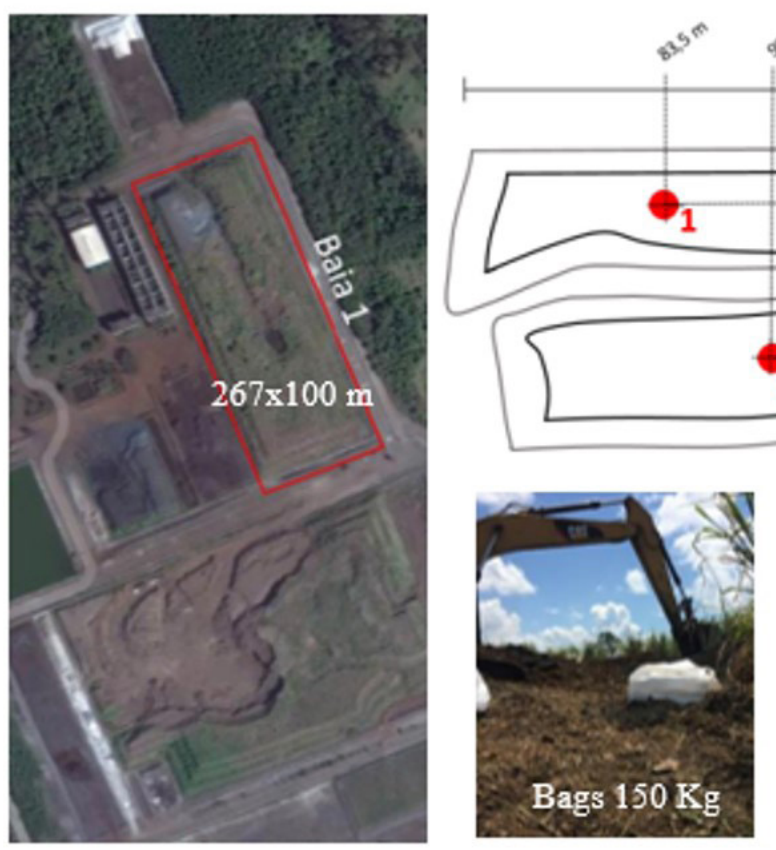

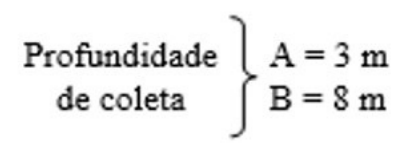

Classificação da coleta em peneiras

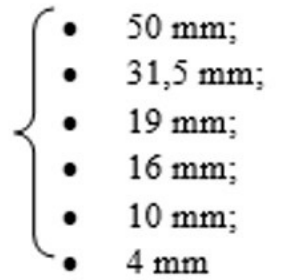

Figura 1. Baia de Fluffy da empresa metalúrgica e pontos de recolhimento das amostras [3]. 
os rejeitos da etapa de trituração da sucata (Fluffy) realizada em Shredder de uma indústria metalúrgica.

$\mathrm{O}$ solo utilizado foi secado em estufa à temperatura de $110^{\circ} \mathrm{C}$ até obter peso constante, e cominuído em moinho de martelo da marca TECNAL modelo TE-330. O solo desaglomerado foi caracterizado quanto a granulometria, em peneiras de \#28, \#42 e \#60mesh, com intuito de quantificar o teor de areia e de finos (silte e argila) presentes. O solo também foi caracterizado por picnometria (massa específica real), microestrutura por difratometria de raios X (DRX) realizado no difratômetro da marca Panalytical, modelo Empire com tubo de cobre, $2 \theta=5-80^{\circ}$ e passo angular $0.002 \mathrm{e}$ microscopia ótica (MO). O microscópio ótico metalográfico utilizado foi da marca KONTROL, modelo IM 713, por uma câmera da marca FORTEL acoplada.

Aproximadamente $400 \mathrm{~g}$ de resíduo de vidro foi previamente triturado em pilão de aço, e dividido em três partes para moagem em moinho de alta energia da marca RETSCH modelo PM-100, por oito minutos com velocidade angular de $300 \mathrm{RPM}$, sendo caracterizado por granulometria, $\mathrm{MO}$, picnometria e DRX.

No ensaio de picnometria foi realizado conforme a NBR ABNT 6458:16 [7], sendo calculado conforme a Equação 1, onde $\rho$ r é a densidade real $\left(\mathrm{em} \mathrm{g} / \mathrm{cm}^{3}\right) ; m_{s}$ é a massa seca da amostra (em gramas); $M$ é massa do picnômetro com água somado a massa da amostra seca (em gramas); $M_{1}$ é a massa do picnômetro com água e com a amostra (em gramas); e $\rho_{\text {ägua }}$ é a densidade da água na temperatura registrada durante o ensaio $\left(\mathrm{em} \mathrm{g} / \mathrm{cm}^{3}\right)$.

$$
\rho r=\frac{m_{S}}{M-M_{1}} \times \rho_{\text {água }}
$$

O ensaio de DRX foi realizado no Difratômetro da marca Panalytical, modelo Empyreando com tubo de cobre, $2 \theta=5-80^{\circ}$ e passo angular 0,002 . As amostras de solo, cimento e vidro foram analisadas na forma de pó, contudo a análise dos corpos de prova foi feita com os fragmentos. Os picos foram identificados por comparação com as fichas JCPDS, utilizando o programa XPert High Score Plus e para o tratamento dos dados foi utilizado o OringPro 8.

Foram realizadas misturas de solo, resíduo de vidro e cimento nas proporções mostradas na Tabela 1. A proporção utilizada nos tijolos de solo-cimento denominada SVC 721 foi similar à comercial $(67 \%$ de solo, $22 \%$ de areia e $11 \%$ de cimento), e considerada como base para definir as outras composições estudadas.

As misturas foram preparadas manualmente, sendo o pó de vidro e o solo pesados e misturados antes de ser adicionado o cimento, e posteriormente toda a matéria prima foi misturada até o aspecto uniforme. A água foi adicionada por meio de aspersão para garantir a melhor homogeneização com os componentes sólidos.

O limite de liquidez (LL) do solo utilizado neste trabalho foi de $44 \%$, o limite de plasticidade (LP) foi de $30 \%$ e o índice de plasticidade (IP) de 14\% [8]. A norma ABNT NBR 10833:2013 [9] indica os valores de LL $\leq$
Tabela 1. Composições das amostras

\begin{tabular}{lccc}
\hline & SOLO (\%) & $\begin{array}{c}\text { RESíDUO DE } \\
\text { VIDRO (\%) }\end{array}$ & CIMENTO (\%) \\
\hline SVC442 & 40 & 40 & 20 \\
SVC532 & 50 & 30 & 20 \\
SVC622 & 60 & 20 & 20 \\
SVC541 & 50 & 40 & 10 \\
SVC631 & 60 & 30 & 10 \\
SVC721 & 70 & 20 & 10 \\
\hline
\end{tabular}

$45 \%$, IP $\leq 18 \%$ para aplicação em tijolo solo-cimento. Quando LL $>45 \%$ e IP $>18 \%$ os processos de secagem, destorroamento e mistura com os outros componentes são prejudicados [10]. As variações na porcentagem de água são diretamente influenciadas pelo valor de LL (que indica a mudança do estado líquido para o plástico) e de LP (menor teor de umidade que faz com que o solo tenha comportamento plástico) [11].

A quantidade de água utilizada na mistura de cada composição foi determinada pela consistência a partir de um teste visual e manual, muito utilizada na indústria de tijolo solo-cimento. Para tal, uma amostra de solo foi umidificada, homogeneizada e apertada na palma da mão até que esta ficasse com um formato compacto consistente. A umidade ideal foi atingida quando o compacto, ao ser partido ao meio, não esfarelasse ou grudasse na mão. A quantidade de água utilizada para moldar variou entre $20 \%$ (para composições mais plásticas, ou seja, com maior teor de solo) e $40 \%$ (para composições com maior teor de resíduo de vidro), em massa, que estão entre os valores de LL e LP do solo utilizado

As misturas foram prensadas no formato de corpo de prova retangular com dimensões $120 \times 30 \times 5 \mathrm{~mm}$, em prensa uniaxial BOVENAU, modelo P15000-15ST, com carga de 2 toneladas, por 30 segundos. Em seguida, os 18 corpos de prova foram submetidos ao processo de cura, por aspersão de água por 7 dias, e foram caracterizados por ensaio de absorção de água, picnometria, DRX e MO.

O ensaio de absorção de água foi realizado baseado nos parâmetros estabelecidos pela ABNT NBR 8492 [12], sendo determinada pela Equação 2, onde $A b s$ é a absorção de água (em \%); $m$ é a massa saturada (em gramas); e $m_{0}$ é a massa seca (em gramas).

$$
A b s=\frac{\left(m-m_{0}\right)}{m_{0}} .100
$$

O ensaio de resistência à flexão foi baseado nos parâmetros estabelecidos pela ABNT NBR ISO 10545-4:2020 [13] e calculada pela Equação 3, onde $F$ é a resistência à flexão; $F a$ é a força aplicada para fraturar a amostra; $L$ é a distância entre os roletes; $b$ é a largura da amostra; e $h$ é a altura da amostra.

$$
F=\frac{3 F_{a} L}{2 b h^{2}}
$$




\section{Resultados}

Na Figura 2 tem-se a imagem do Fluffy (a), alguns resíduos de vidro de diferentes tamanhos e cores retirados do Fluffy após a lavagem com água em separador de peneiras (b) e o pó de vidro obtido após moagem em moinho de alta atrição (c).

A análise granulométrica do resíduo de pó de vidro apresenta partículas menores que $0,60 \mathrm{~mm}$, e do solo menores que $0,85 \mathrm{~mm}$, indicando características morfológicas similares. A curva granulométrica do resíduo do pó de vidro e do solo são apresentadas na Figura 3.

Galvão et al. [6] afirma que para a estabilização com cimento, os solos devem conter uma fração de silte e argila variando de $10 \%$ a $35 \%$.

Solos com uma quantidade de finos (silte e argila) inferior a $10 \%$, geram dificuldade na sua compactação e o acabamento pode ficar prejudicado.

De acordo com a ABNT NBR 6502 [14], é considerado areia grossa partículas de $0,6-2 \mathrm{~mm}$, areia média de $0,2-0,6 \mathrm{~mm}$, areia fina de $0,06-0,2 \mathrm{~mm}$, silte de 0,002-0,06, e argila partículas menores que $0,002 \mathrm{~mm}$. Desta forma, o solo utilizado possui $51 \%$ de areia média, $16 \%$ de areia grossa, $33 \%$ compreende areia fina com silte e argila, sendo indicado para tijolos de solo-cimento e extrapolado para placas de solo-cimento. $\mathrm{O}$ pó de vidro poderia ser enquadrado como areia, sendo $22 \%$ de granulometria média, e $78 \%$ de areia fina com silte e argila, vindo a colaborar para compensar a granulometria do solo.

Os difratogramas de raios $\mathrm{X}$ do pó de solo, do cimento e do resíduo de vidro são mostrados na Figura 4. No difratograma do solo, foram encontradas as fases caulinita e quartzo. A caulinita é um argilomineral que possui baixo poder de retenção de água, além de possuir uma fraca carga eletronegativa. Por adquirir plasticidade com baixos teores de água, a presença desta se torna essencial para a produção de placa solo-cimento, já que este é produzido a partir de conformação mecânica [15]. No difratograma do cimento, foram encontradas as fases do silicato de cálcio, do carbonato de cálcio e óxido de cálcio, alumínio e ferro. A presença dessas fases é explicada pela ausência de material pozolânico e de escória de alto forno no cimento, visto que o CPV-ARI, diferente de outros tipos de cimentos, é composto apenas de clínquer e calcário [16]. É possível observar no difratograma do resíduo de vidro que não há presença de picos característicos de fases cristalinas, e, portanto, tem estrutura amorfa, típico de vidros comuns.

Possivelmente, o pó de vidro é isento de possíveis contaminações do processo de moagem, ou estas são inferiores a 3\% referentes ao limite de detecção do difratômetro.

Na Figura 5a, é possível observar a superfície homogênea dos corpos de prova, com coloração avermelhada típica dos constituintes argilosos do solo, ficando ligeiramente mais clara para maiores quantidades de vidro na composição.
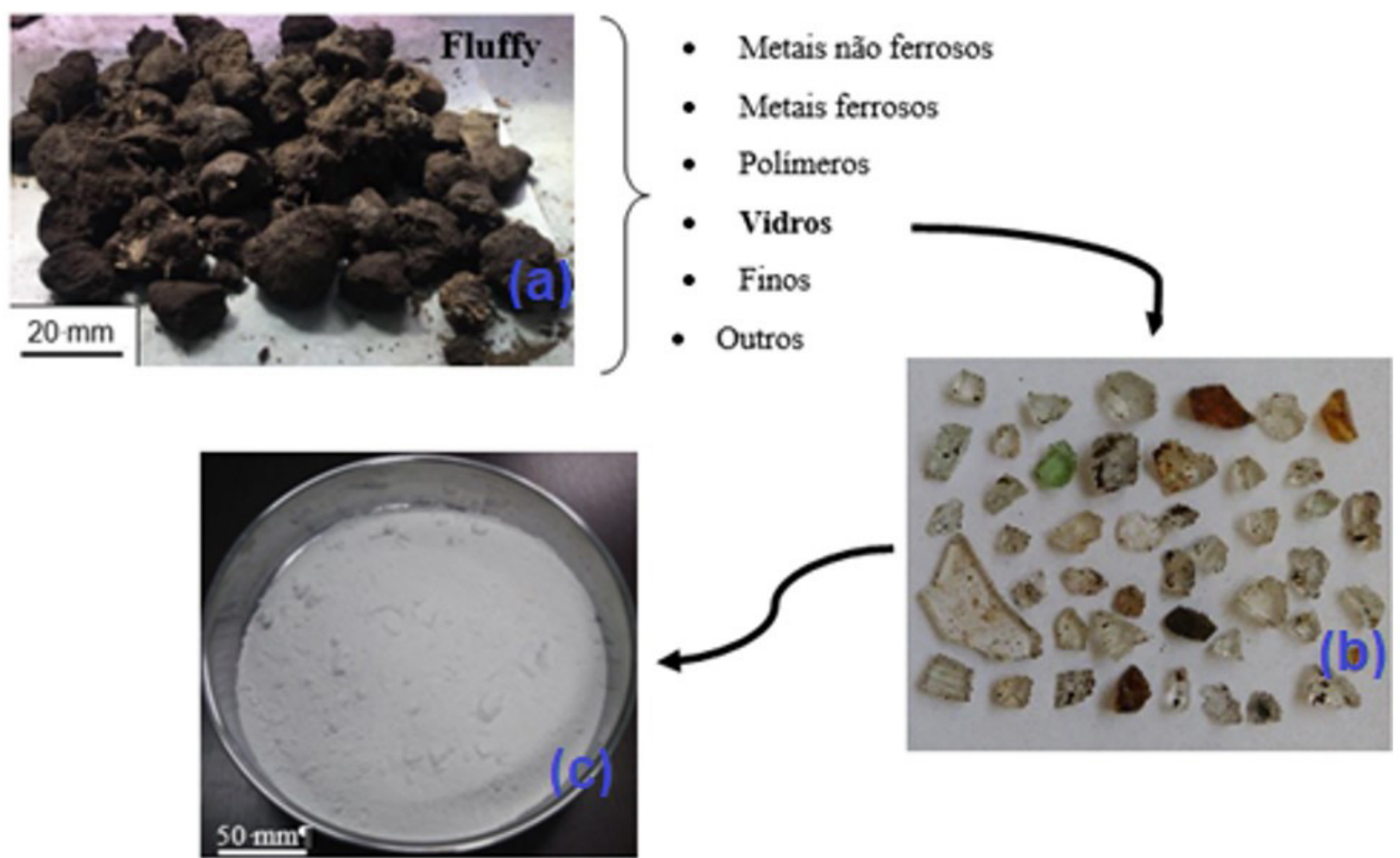

Figura 2. Imagem (a) rejeito da etapa de trituração de sucata em Shredder de indústria metalúrgica (Fluffy); (b) resíduos de vidro extraídos do Fluffy; e (c) pó de vidro obtido em moinho de alta atrição. 


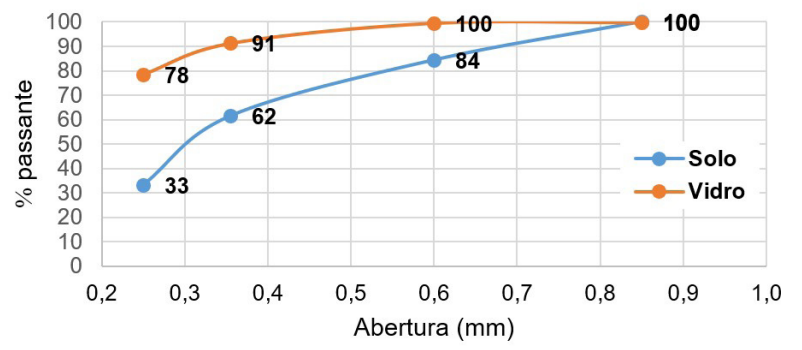

Figura 3. Curva granulométrica do pó de vidro e do solo.

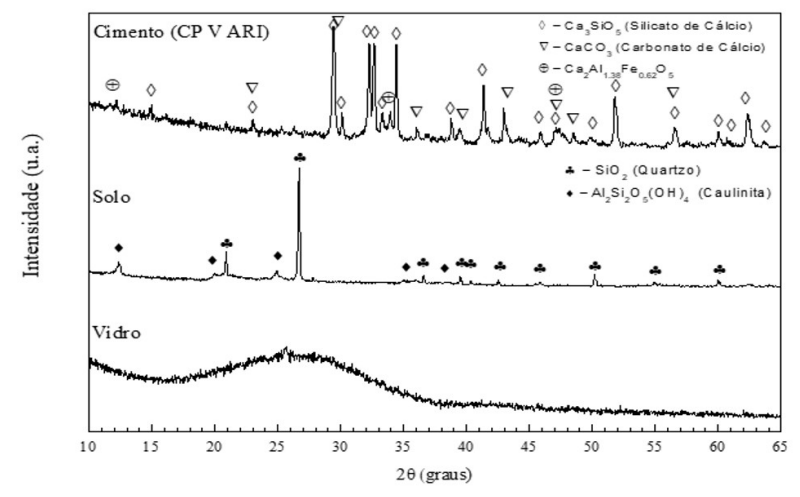

Figura 4. Difratograma de raios $\mathrm{X}$ das matérias primas.
A Figura 5b, está a micrografia da superfície da amostra SVC721, e a Figura 5c, está a micrografia da SVC442. Pode-se observar grãos brilhantes típicos de quartzo presente no solo e/ou partículas de pó de vidro, que acabam por refletirem com a luz incidente do estereoscópio óptico. Pode-se observar a presença de porosidades (pontos escuros) em toda a superfície das amostras, o que é natural para produtoscimentícios tipo solo-cimento.

As microestruturas das demais amostras são similares às mostradas.

$\mathrm{O}$ difratograma de raios $\mathrm{X}$ dos corpos de prova após a cura são mostrados na Figura 6. Pode-se observar que as fases encontradas nas matérias-primas se mantêm nos corpos de prova. Nestes foram encontradas as fases de quartzo, caulinita, silicato de cálcio e o carbonato de cálcio. A caulinita presente na fração fina do solo é o componente que fornece sua característica plástica, pois tem maior capacidade de retenção de água quando comparada as frações de silte e quartzo. Tendo em vista que o objetivo é a produção de placas mediante a conformação mecânica, a presença da caulinita no solo é fator determinante para a trabalhabilidade da mistura [17].

Os resultados médios de absorção de água dos corpos de prova são mostrados na Figura 7. Com o aumento da idade dos corpos de prova os valores de absorção de água
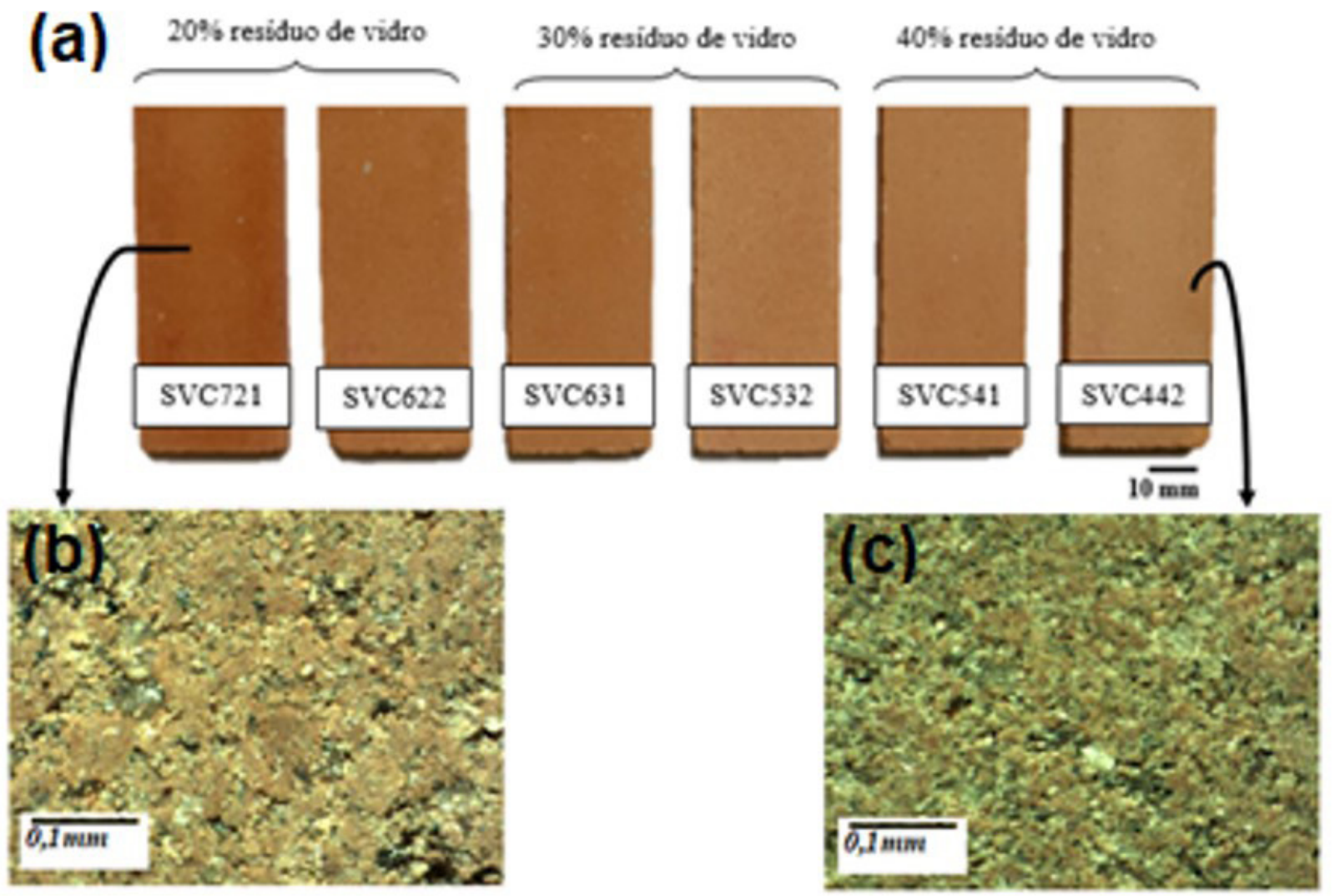

Figura 5. (a) Imagem macro dos corpos de prova; (b) Micrografia da superfície de amostra SVC721; e (c) Micrografia da superfície da amostra SVC442. 


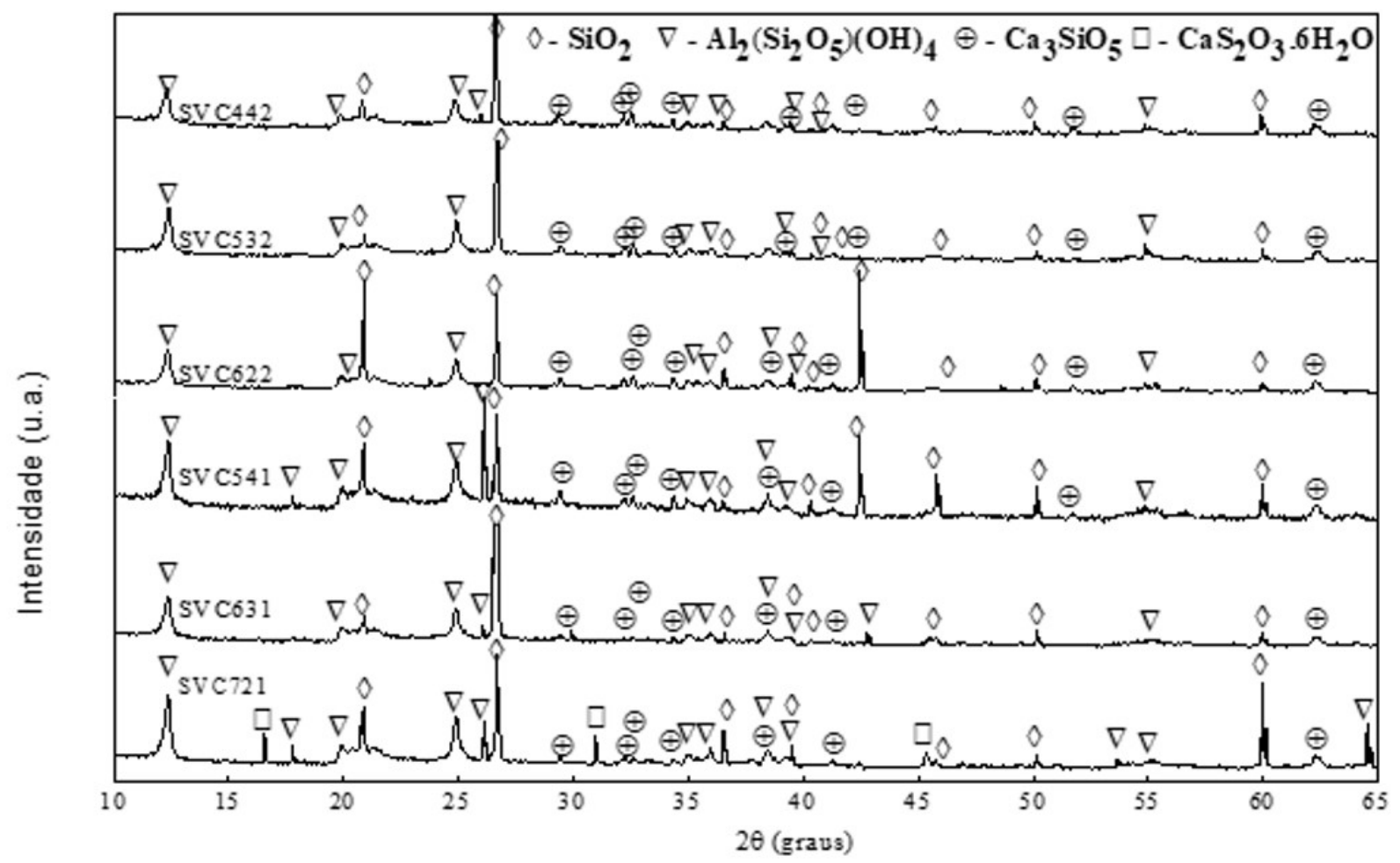

Figura 6. Difratograma de raios $X$ dos corpos de prova após a cura.

diminuem, indicando que o processo de cura ainda se processa ao longo do tempo [17].

A absorção de água é diretamente influenciada pelos componentes do solo, os quais tem maior capacidade de retenção de umidade [15,17]. Conforme a Figura 7, o aumento do teor de solo na mistura acarreta o aumento dos valores de absorção de água. É possível observar que a amostra SVC442, que possui menor teor de solo na mistura, foi aquela que apresentou os menores resultados de absorção de água.

Por outro lado, as amostras com maior porcentagem de vidro apresentam menor absorção de água, sendo favorável à maior utilização de resíduo incorporado na composição. As amostras com $20 \%$ de cimento na mistura apresentaram menores absorções de água quando comparado com $10 \%$.

Os valores de massa específica dos corpos de prova também são mostrados na Figura 7, cujos valores variaram de 1,344 a $1,773 \mathrm{~g} / \mathrm{cm}^{3}$. A massa específica média do pó de vidro encontrada foi de $\rho=2,389 \pm 0,148 \mathrm{~g} / \mathrm{cm}^{3}$, valor similar ao encontrado por Paiva [18] que obteve $\rho=2,340 \mathrm{~g} / \mathrm{cm}^{3}$. A massa específica média do solo foi de $\rho=2,021 \pm 0,051 \mathrm{~g} / \mathrm{cm}^{3}$, valor $25,73 \%$ menor ao encontrado por Rodrigues e Holanda [19] que obteve $\rho=2,720 \mathrm{~g} / \mathrm{cm}^{3}$. Foi verificado que, independentemente da quantidade de resíduo de vidro incorporada, os valores de massa específica dos corpos de prova são menores quando comparados com seus pós individualmente antes da mistura. Isto pode ser atribuído ao processo de evaporação da água durante o

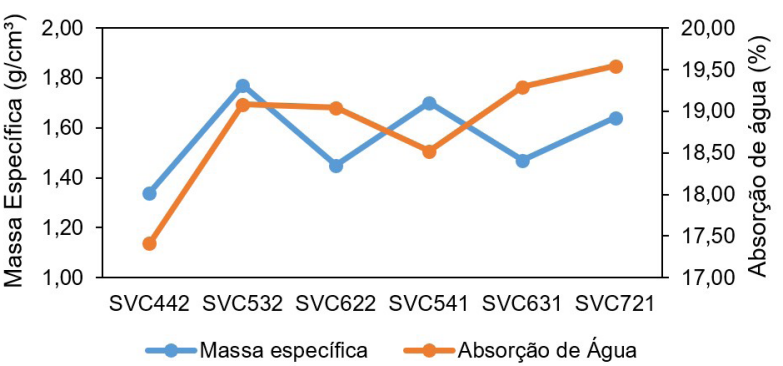

Figura 7. Média dos valores de absorção de água (com 95\% de confiabilidade) e da massa específica das amostras após 28 dias.

processo de cura, deixando porosidade na peça e refletindo nos resultados de massa específica $[17,19]$.

Os valores de resistência à flexão estão entre $2,22 \mathrm{MPa}$ a 4,66 MPa, conforme a Figura 8. Segundo a literatura, as composições que apresentam menores valores de absorção de água consequentemente apresentam maiores valores de resistência mecânica devido à maior densidade dos corpos de prova $[20,21,22]$. Pode-se observar, na Figura 8 , que as amostras com 20\% de cimento (SVC442, SVC532 e SVC622) possuem valores de resistência à flexão aproximadamente duas vezes maior que as com $10 \%$, indicando que o maior teor de cimento na composição gera uma placa de solo-cimento mais resistente mecanicamente.

Foi observado na literatura que placas de solo-cimento com teor de cimento de aproximadamente $12 \%$, que pode ser 


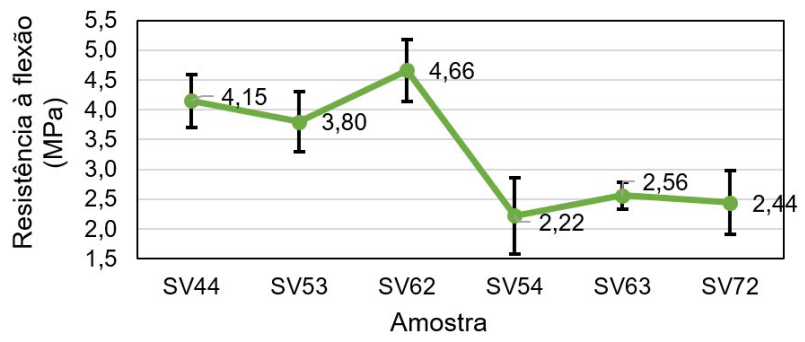

Figura 8. Média dos valores de resistência à flexão com $95 \%$ de confiabilidade.

considerado semelhante a proporção comercial de 6:2:1 (67\% de solo, $22 \%$ de areia e $11 \%$ de cimento), a resistência à flexão foi de 1,22 MPa [23]. Desta forma, é possível inferir que a inserção de vidro na composição pode ter contribuído positivamente para melhorar a resistência à flexão dos corpos de prova obtidos neste trabalho.

A amostra SVC442 possui o menor valor de absorção de água, elevado valor de resistência à flexão, e é composta de $40 \%$ de resíduo de vidro. A utilização do resíduo de vidro oriundo do Fluffy contribui não somente na mitigação dos impactos ambientais da indústria metalúrgica como poderia minimizar a quantidade de matéria prima comercial utilizada no placa solo-cimento. Ambos fatores podem impactar positivamente nos custos diretos e indiretos da indústria metalúrgica e também do produto cimentício. Embora a composição SVC622 tenha apresentado maior valor de resistência à flexão dentre as composições estudadas, esta tem apenas $20 \%$ de resíduo de vidro e a absorção de água não foi tão baixa quanto SVC442.

É importante ressaltar que a indústria de cimento é responsável por elevada emissão de $\mathrm{CO}_{2}$ e, portanto, aumentar sua utilização na composição da placa de solocimento, mesmo que em $10 \%$, influencia indiretamente nos impactos ambientais. Por outro lado, o fato de a placa de solo-cimento não precisar ser queimada, pode compensar, integralmente ou parcialmente, a utilização do cimento neste produto, como forma de aproveitar o resíduo de vidro das empresas metalúrgicas. Cabe salientar que o resíduo de vidro oriundo do Fluffy pode conter impurezas, e, portanto, não é facilmente agregado no processo de reciclagem de vidro tradicional, mas pode ser aplicado para a produção de placa de solo-cimento.

\section{Conclusões}

Os valores de absorção de água e resistência à flexão dos corpos de prova para todas as composições estudadas foram aceitáveis quando comparados ao que se espera para produtos similares, como o tijolo de solo-cimento, indicando que a inserção do resíduo de vidro oriundo de indústria metalúrgica poderia ser utilizada para produção de placa de solo-cimento.

Os melhores resultados de absorção de água (abaixo de $18 \%)$, maiores resistências à flexão (de 4,15 MPa) e elevado aproveitamento de resíduo de vidro (40\%) foram das amostras SVC442, e, portanto, é a composição indicada para produção de placa solo-cimento.

Como esperado, o aumento de $10 \%$ para $20 \%$ de cimento na composição praticamente dobrou os valores de resistência a flexão, devido suas propriedades aglomerantes que promovem maior coesão entre os constituintes, no entanto, não influenciou de forma significativa nos resultados de absorção de água.

Este trabalho indica que existe um potencial para a incorporação de resíduo de pó de vidro na massa de placa de solo-cimento, agregando valor a este, e incentivando à minimização da quantidade de Fluffy de trituradora Shredder nos pátios de metalúrgicas. A integração entre os setores industriais pode promover a engenharia sustentável, por meio do aproveitamento racional dos resíduos gerados, principalmente porque o volume produzido pelas metalúrgicas são representativos.

\section{Referências}

1 Reckziegel VN. Caracterização para o aproveitamento do resíduo de um triturador de sucata em uma usina siderúrgica [dissertação]. Rio Grande do Sul: Universidade Federal do Rio Grande do Sul; 2012.

2 Ciuccio M. Estudo de tendências e oportunidades no desenvolvimento sustentável para a reciclagem de veículos e seus materiais [dissertação]. São Carlos: Universidade Federal de São Carlos; 2004.

3 Medeiros G, Vaz G. Avaliação do teste de emprego do fluffy no FEA2 da Cosigua. Informe Técnico: Processos Aciaria. 2010;(49):1-9.

4 Zevenhoven R, Saeed L. Automotive shredder residue (ASR) and compact disc (CD) waste: options for retkk-covery of materials and energy: report TKK-ENY-14. Finland: Helsinki University of Technology; 2003.

5 Silva FFC, Brasileiro GAM, Silva IS, Feitosa VFL. Tijolo de solo-cimento com adição de fibras de coco como alternativa sustentável para construção. Revista Expressão Científica. 2018;3:46-52.

6 Galvão ÁCP, Farias ACM, Souza LGM. Viabilização de rejeitos de vidro para produção de tijolos cerâmicos. HOLOS. 2013; 4:59-69 vermelhas com adição de rejeito de rocha ornamental isenta de granalha. Cerâmica. 2012;58:286-293. 
7 Associação Brasileira de Normas Técnicas - ABNT. NBR 6458: grãos de pedregulho retidos na peneira de abertura 4,8 mm: determinação da massa específica, da massa específica aparente e da absorção de água. Rio de Janeiro: ABNT; 2017.

8 Teixeira FP. Processamento e caracterização de corpos de prova de tijolo solo-cimento [monografia]. Seropédica: Universidade Federal Rural do Rio de Janeiro; 2018.

9 Associação Brasileira de Normas Técnicas - ABNT. NBR 10833: fabricação de tijolo e bloco de solo-cimento com utilização de prensa manual ou hidráulica: procedimento. Rio de Janeiro: ABNT; 2013.

10 Pinheiro BJR, Soares DMJ. Utilização de solos arenoso para obtenção de tijolos solo-cimento. Cerâmica Industrial. 2010;15:30-36.

11 Vasconcelos RFB, Cantalice JRB, Silva AJN, Oliveira VS, Silva YJAB. Limites de consistência e propriedades químicas de um latossolo amarelo distrocoeso sob aplicação de diferentes resíduos da cana-de-açúcar. Revista Brasileira de Ciência do Solo. 2010;34:639-648.

12 Associação Brasileira de Normas Técnicas - ABNT. NBR 8492: Tijolo de solo-cimento: análise dimensional, determinação da resistência à compressão e da absorção. Rio de Janeiro: ABNT; 2012.

13 Associação Brasileira de Normas Técnicas - ABNT. NBR ISO 10545-4: Placas cerâmicas. Parte 4: determinação da carga de ruptura e módulo de resistência à flexão. Rio de Janeiro: ABNT; 2020.

14 Associação Brasileira de Normas Técnicas - ABNT. NBR 6502: Rochas e solos. Rio de Janeiro: ABNT; 1995.

15 Grande FM. Fabricação de tijolos modulares de solo-cimento por prensagem manual com e sem adição de sílica ativa [dissertação]. São Carlos: Universidade de São Paulo; 2003.

16 Associação Brasileira de Normas Técnicas - ABNT. NBR 16697: Cimento Portland - Requisitos: Rio de Janeiro: ABNT; 2018.

17 Lima TV. Estudo da produção de blocos de solo-cimento com matéria-prima do núcleo urbano da cidade de Campos dos Goytacazes - RJ [dissertação]. Campos dos Goytacazes: Universidade Estadual do Norte Fluminense; 2006.

18 Paiva AO. Resíduo industrial de vidro moído em argamassa de cimento Portland. [dissertação]. Manaus: Universidade Federal do Amazonas; 2009.

19 Rodrigues LP, Holanda JNF. Influência da incorporação de lodo de estação de tratamento de água (ETA) nas propriedades tecnológicas de tijolos solo-cimento. São Paulo. Cerâmica. 2013;59:551-556.

20 Ribeiro SV. Reutilização de resíduo de rocha ornamental na produção de tijolo solo-cimento [dissertação]. Campos dos Goytacazes: Universidade Estadual do Norte Fluminense; 2013.

21 Miyahara RY, Furlan GHRH, Valenzuela-Dias FR, Toffoli SM. Correlação entre medidas de resistência mecânica de corpos de prova argila conformados manualmente por prensagem uniaxial. In: Anais do $48^{\circ}$ Congresso Brasileiro de Cerâmica; 2004 Jun. 28-Jul. 1; Curitiba, Brasil. São Paulo: ABCERAM; 2004. p. 2260-2269.

22 Taguchi SP, Santos JC, Gomes TM, Cunha NA. Avaliação das propriedades tecnológicas de cerâmica vermelha incorporada com resíduo de rocha ornamental proveniente do tear de fio diamantado. Cerâmica. 2014;60:291-296.

23 Venkatarama Reddy BV, Gupta A. Characteristics of soil cement blocks using highly sandy soils. Materials and Structures. 2005;38:651-658.

Recebido em: 4 Out. 2020

Aceito em: 26 Mar. 2021 